\title{
Plan and road map for health reform in Iran
}

The author affiliation (BMJ 2015;351:h4407, doi:10.1136/bmj. h4407) for Mohammadkarim Bahadori should have read "Health Management Research Center, Baqiyatallah University of

Cite this as: BMJ 2015;351:h4589

Medical Sciences, Tehran, Iran." 